\title{
Incidence of SUDEP in a cohort of patients with refractory epilepsy The role of surgery and lesion localization
}

\author{
Andrea Garcia de Almeida', Magda Lahorgue Nunes², \\ André Luis Fernandes Palmini ${ }^{3}$, Jaderson Costa da Costa ${ }^{4}$
}

\begin{abstract}
Objective: The aim of this study was to verify incidence and characteristics of sudden unexpected death in patients (SUDEP) with refractory epilepsy and its relation to previous surgery and lesion localization. Method: A cross sectional study was carried out in a cohort of 550 patients with refractory epilepsy followed up by the Epilepsy Surgery Program of the University Hospital of PUCRS, Porto Alegre, Brazil, between January, 1992 and July, 2002. Patients were allocated in two groups (operated and non operated). Seizure type, distribution of interictal spikes and MRI findings were correlated with the SUDEP outcome. Results: The estimated incidence of probable SUDEP amounted to 29:1000 individuals. Probable SUDEP occurred in $1.2 \%$ of the 166 patients of the non operated group and in $3.7 \%$ of the 384 patients who were operated (OR=3.02, 95\% Cl 0.69-13.16) $(p=0.11)$. Comparing patients who died to patients alive in the operated group a significant difference was observed concerning the following variables: SUDEP patients had a predominance of generalized seizures $(p=0.002)$, extratemporal lesion on MRI $(p<0.001)$ and epileptiform activity over extratemporal regions ( $p=0.001)$. Conclusion: In surgically treated patients with refractory epilepsy, an extratemporal location of the lesion and of the epileptiform discharges significantly correlated to SUDEP. Thus it is possible that in those patients; the underlying disease may play a role in the pathogenesis of SUDEP.
\end{abstract}

Key words: SUDEP, refractory epilepsy, epilepsy surgery, extratemporal epilepsy.

Incidência de SUDEP numa coorte de pacientes com epilepsia refratária: papel da cirurgia e da localização da lesão

\section{RESUMO}

Objetivo: $O$ objetivo deste estudo é avaliar a incidência e características de morte súbita em pacientes com epilepsia refratária (SUDEP) e sua relação com cirurgia prévia e localização da lesão. Método: Estudo de Coorte realizado com 550 pacientes com epilepsia refratária seguidos no Programa de Epilepsia do Hospital Universitário da PUCRS, Porto Alegre, Brasil, entre Janeiro, 1992 e Julho, 2002. Os pacientes foram distribuídos em dois grupos (operados e não operados). Tipo de epilepsia, distribuição das descargas interictais e achados em RNM foram correlacionados com SUDEP. Resultados: A incidência estimada de SUDEP foi 29:1000 indivíduos. A incidência de provável SUDEP nos 166 pacientes do grupo de não operados foi $1,2 \%$ e nos 384 pacientes no grupo operado 3,7\% (OR=3,02, 95\% IC 0,69-13,16) $(p=0,11)$. Comparando os pacientes que morreram com os sobreviventes do grupo operado houve diferença significativa nas seguintes variáveis: pacientes com SUDEP apresentam uma predominância de crises epilépticas generalizadas $(p=0,002)$, lesões extratemporais na RNM $(p<0,001)$ e atividade epileptiforme na região extratemporal $(p=0,001)$. Conclusão: $A$

Correspondence

Magda Lahorgue Nunes Division of Neurology São Lucas Hospital - PUCRS Av. Ipiranga 6690 / 220 90610-000 Porto Alegre RS - Brasil E-mail: nunes@pucrs.br

Received 25 February 2010

Received in final form 6 May 2010 Accepted 13 May 2010 localização da lesão e as descargas extratemporais em pacientes tratados cirurgicamente com epilepsia refratária correlacionaram-se significativamente com SUDEP. Então, é possível que nestes pacientes uma doença sobrejacente possa estar envolvida na patogênese da SUDEP. Palavras-chave: SUDEP, epilepsia refratária, cirurgia da epilepsia, epilepsia extratemporal.

Division of Neurology, Epilepsy Surgery Program, São Lucas Hospital, Pontifícia Universidade Católica do Rio Grande do Sul (PUCRS), Porto Alegre RS, Brazil: ${ }^{1}$ Neurologist, Division of Neurology of São Lucas Hospital; ${ }^{2}$ Associate Professor of Neurology and Pediatrics at the School of Medicine, PUCRS; ${ }^{3}$ Associate Professor of Neurology at the School of Medicine, PUCRS: ${ }^{4}$ Professor of Neurology at the School of Medicine, PUCRS. 
Sudden unexpected death in refractory epilepsy was defined as sudden death, with or without signs of a seizure, excluding evidence of status epilepticus, in which postmortem examination did not disclose the cause of death $(\mathrm{SUDEP})^{1}$. It is more common in patients with epilepsy when confronted with the general population ${ }^{2}$; accounting for an incidence of $1 / 1.000$ cases $^{3-5}$. The highest SUDEP rates, 9/1.000 person-years, have been reported in candidates for epilepsy surgery and in patients in whom surgery failed to control seizures (15 per 1.000 cases) $)^{6,7}$.

Among the well known risk factors for SUDEP such as male sex, age between 20 and 40 years, generalized seizures, poor seizure control and poor compliance with medication, most of previous studies have not focused on lesion localization ${ }^{8-10}$. A particular risk for SUDEP was suggested in studies with groups from autopsy series that presented focal central nervous system lesions ${ }^{11-14}$, however these findings were not supported in case-control studies $^{15,16}$. By now, available data do not yet allow firm conclusions to be made about the effect of epilepsy surgery on the risk of SUDEP ${ }^{17}$. SUDEP was also not associated with any particular type of epilepsy, such as localization-related symptomatic or cryptogenic epilepsy ${ }^{18}$.

The present study was conducted to examine the incidence and characteristics of SUDEP in patients with refractory epilepsy and its possible relation to surgical treatment and lesion localization.

\section{METHOD}

A cross sectional study was carried out in a cohort of 550 patients with refractory epilepsy followed up by the Epilepsy Surgery Program of the Neurology and Neurosurgery Services of São Lucas Hospital, which is the University Hospital of Pontificia Universidade Católica do Rio Grande do Sul (PUCRS), between January, 1992 and July, 2002. Patients were allocated to one of two groups: Group 1 included 166 patients with refractory partial epilepsy, candidates for epilepsy surgery, waiting for hospital admission and presurgical evaluation, whereas group 2 included 384 surgically treated patients. The incidence of sudden death, as well as the mortality rate, was assessed in these patients.

The diagnosis of epilepsy and its type were based on history, physical examination, surface EEG and neuroimaging particularly magnetic resonance imaging (MRI).

Seizures were classified as generalized or focal. Following presurgical evaluation, epilepsy was classified as symptomatic, when one or more etiologies were identified by MRI, or cryptogenic, which were presumed to be symptomatic, but with normal MRI and unknown etiology ${ }^{19,20}$.

Definite SUDEP was defined as sudden, unexpected, witnessed or unwitnessed, nontraumatic, and nondrowning death in patients with epilepsy, with or without evi- dence of a seizure and excluding documented status epilepticus. By definition, necropsy examination did not reveal any toxicological or anatomical cause of death. In the lack of autopsy, but still with no alternative explanation for death, SUDEP was considered probable ${ }^{1}$.

The current health status of the patients was assessed by one of the researchers by telephone conversation using a questionnaire. Patients or relatives (in case of death or when patients were unable to be interviewed) were questioned about seizure status and, in those who died, about the circumstances of death (in bed, alone, during a seizure, type of associated seizure, and whether the event was witnessed or not). Seizure outcome was classified according to the modified seizure classification of Engel ${ }^{21}$.

Variables were assessed using the SPSS version 10.0. The test exact Fischer was used to evaluate statistical differences between the groups. The Mann-Whitney test was used to evaluate numeric variables (age, age at onset of the seizures, duration of epilepsy). The odds ratio for death was determined in both groups. A p value less than 0.05 was established as statistically significant. The study protocol was approved by the Institutional Ethics Committee.

\section{RESULTS}

After contacting all patients or relatives, 16 patients were reported to be dead. Definitive cases of SUDEP were not confirmed because no patient underwent autopsy. Previous epilepsy surgery did not correlate with the occurrence of SUDEP. Fourteen (3.7\%) of the 384 patients who had surgery died, compared to $2(1.2 \%)$ of the 166 who were not operated $(\mathrm{OR}=3.02,95 \% \mathrm{CI}$ 0.69-13.16) $(\mathrm{p}=0.11)$ (Table 1). The estimated incidence of SUDEP among the patients followed up by the Epilepsy Surgery Program (surgical candidates and surgically treated patients) amounted to 29 cases per 1.000 individuals. Its incidence among surgical candidates and surgically treated patients was, respectively, 12 cases per 1.000 and 36 cases per 1.000 inhabitants

Clinical characteristics of the operated group were described in Table 2. Among 384 operated patients, 221 (57.6\%) were operated for temporal epilepsy and 163 (42.4\%) for extratemporal epilepsy. Comparing patients

Table 1. Sudden unexpected death in refractory epilepsy (SUDEP) in patients submitted to epilepsy surgery and patients that were on the waiting list for epilepsy surgery.

\begin{tabular}{|c|c|c|c|}
\hline \multirow[b]{2}{*}{ Group } & \multicolumn{2}{|c|}{ SUDEP } & \multirow[b]{2}{*}{ Total } \\
\hline & Yes & No & \\
\hline Operated & 14 & 370 & 384 \\
\hline Non operated & 2 & 164 & 166 \\
\hline Total & 16 & 534 & 550 \\
\hline
\end{tabular}

Odds ratio (OR): 3.02 , IC 95\% OR=(0.69;13.16) $(\mathrm{p}=0.11)$. 
Table 2. Clinical characteristics and outcome of the 384 operated patients.

\begin{tabular}{|c|c|c|c|}
\hline Variables/outcome & $\begin{array}{c}\text { Alive } \\
(n=370)\end{array}$ & $\begin{array}{l}\text { SUDEP } \\
(n=14)\end{array}$ & $\mathrm{p}$ \\
\hline Age (years) & $25.6 \pm 13.2$ & $14.0 \pm 18.6$ & $0.34^{\mathrm{a}}$ \\
\hline Age at onset of the seizures & $4.5 \pm 8.5$ & $0 \pm 7.9$ & $0.15^{\mathrm{a}}$ \\
\hline Duration of epilepsy (years) & $17 \pm 11.8$ & $8.5 \pm 18.4$ & $0.76^{\mathrm{a}}$ \\
\hline Male sex & $213(57.5 \%)$ & $8(57.1 \%)$ & 0.95 \\
\hline \multicolumn{4}{|l|}{ Type of seizure } \\
\hline Generalized & $31(8.4 \%)$ & $2(14.3 \%)$ & \multirow[t]{2}{*}{0.002} \\
\hline Partial & $339(91.6 \%)$ & $12(85.7 \%)$ & \\
\hline \multicolumn{4}{|l|}{ Type of epilepsy } \\
\hline Cryptogenic & $58(15.7 \%)$ & $3(21.4 \%)$ & \multirow[t]{2}{*}{0.47} \\
\hline Symptomatic & $312(84.3 \%)$ & $11(78.6 \%)$ & \\
\hline \multicolumn{4}{|l|}{ Video-electroencephalogram } \\
\hline EATR & $218(58.9 \%)$ & $3(21.4 \%)$ & \multirow[t]{2}{*}{0.01} \\
\hline EAER & $152(51.1 \%)$ & $11(78.6 \%)$ & \\
\hline \multicolumn{4}{|l|}{ Magnetic resonance imaging } \\
\hline Normal & $56(15.1 \%)$ & $3(21.4 \%)$ & \multirow[t]{3}{*}{$<0.001$} \\
\hline Hipocampal sclerosis & $198(53.5 \%)$ & $1(7.1 \%)$ & \\
\hline Extratemporal lesion & $116(31.4 \%)$ & $10(71.4 \%)$ & \\
\hline \multicolumn{4}{|c|}{ Engel classification for surgery outcome } \\
\hline Class I & $339(91.6 \%)$ & $12(85.7 \%)$ & \multirow[t]{4}{*}{0.34} \\
\hline Class ॥ & 0 & 0 & \\
\hline Class III & 0 & 0 & \\
\hline Class IV & $31(8.3 \%)$ & $2(14.2 \%)$ & \\
\hline \multicolumn{4}{|l|}{ Type of surgery } \\
\hline Focal cortical resection & 370 & 14 & \\
\hline
\end{tabular}

Table 3. Presence of risk factors for SUDEP in the 16 patients with probable SUDEP.

\begin{tabular}{lccc}
\hline Risk factors/Groups & $\begin{array}{c}\text { Operated } \\
\mathrm{n}=14\end{array}$ & $\begin{array}{c}\text { Non operated } \\
\mathrm{n}=2\end{array}$ & $\mathbf{p}$ \\
\hline Male sex & $7(50 \%)$ & $1(50 \%)$ & 0.999 \\
Age $20-40$ & $11(78 \%)$ & $2(100 \%)$ & 0.999 \\
Generalized seizure & $11(78 \%)$ & $2(100 \%)$ & 0.999 \\
Poor seizure control & $14(100 \%)$ & $2(100 \%)$ & 0.999 \\
\hline
\end{tabular}

SUDEP: sudden unexpected death in refractory epilepsy.

with probable SUDEP to patients alive in the operated group, a significant difference was observed concerning the occurrence of generalized seizures ( $\mathrm{p}=0.002)$, of an extratemporal lesion on MRI $(\mathrm{p}<0.001)$ and of epileptiform activity over extratemporal regions $(\mathrm{p}=0.001)$.

The presence of risk factors for SUDEP was similar in patients with probable SUDEP coming from the operated and non operated groups (Table 3).

There were no deaths secondary to the surgical pro- cedure. The frequency of epileptic seizures diminished in all patients in the postoperative period, except for one whose seizures recurred in the first postoperative week. This was the only patient who died during the first postoperative month; the other deaths occurred between 6 to 84 months after surgery. Mean time of death after surgery was $35 \pm 27$ months.

Among the non-operated patients, two died while waiting for surgery. One died at home and on her bed after a brief generalized seizure; she had no previous history of heart disease. The other patient was awaiting surgery for temporal lobe epilepsy and died sleeping in bed at night after a generalized seizure.

\section{DISCUSSION}

Within our large cohort of patients with medically-refractory partial epilepsies, the main findings were that the incidence of SUDEP was similar between operated and non operated patients, waiting to be admitted for presurgical evaluation. In addition, we found that in the operat- 
ed group, the presence of secondary generalized seizures, an extratemporal irritative zone and a structural lesion in extratemporal regions correlated with SUDEP.

Large, non-selected cohorts of patients with medically refractory seizures such as the one studied here tend to present similar profiles in terms of age, seizure duration, seizure frequency and type. In our Center, once patients are identified as potential surgical candidates they enter a presurgical waiting list and are admitted sequentially for evaluation and surgery. There is no bias of referral for presurgical evaluation, particularly because MRI is performed only during inpatient evaluation. Thus, even though we do not report in detail the clinical profile of patients in the waiting list, they certainly share similar features as the ones who had had surgery at the time. These features, thus, are unlikely to have biased the results.

Although improvements in surgical outcome of patients with extratemporal epilepsy have been reported in recent years - mostly due to refinements in patient selection, seizure recurrence following this procedure is still high in comparison to patients operated for temporal epilepsy ${ }^{22,23}$. Pragmatically speaking, thus, we did not find differences in the occurrence of SUDEP in connection with post-surgical seizure status, neither in patients with temporal lobe nor in those with extratemporal lobe epilepsy. Rather, we found that having an extratemporal focus or lesion was the main correlate of SUDEP. Our data do not allow a conclusion as to whether a greater occurrence of secondary generalized seizures in the epilepsy history might have mediated the correlation between SUDEP and extratemporal epilepsy. This may be so, particularly because the occurrence of generalized seizures, per se, correlated with SUDEP in the operated patients. Because SUDEP is less frequent with temporal lobe epilepsy ${ }^{23}$, the message to be retained from our findings is that when following patients operated for extratemporal epilepsy, the risk of SUDEP should be closely considered in those who preoperatively had or post-operatively remain with secondary generalized seizures. An important corollary of this finding is that surgical procedures aiming at alleviating the seizure burden, that is, to control the secondary generalized seizures, may well be valid, even when partial seizures remain refractory to medication. This is not an uncommon scenario, the benefits of which, however, are largely neglected.

An interesting issue raised by our findings concerns the potential reasons why there was no correlation between the occurrence of SUDEP and seizure free status after surgery. One potential explanation relates to the possibility that the secondary generalized seizures, and not all types of seizures, may be relevant for the post-operative risk of SUDEP. Should this be the case, then, whether a patient is or is not seizure free after operation is only relevant if the remaining refractory seizures include secondary generalized seizures. Our data does not allow a firm conclusion about this, but certainly suggest that this may be the case, reinforcing that the control of secondary generalization is a valid surgical goal, irrespective of the anticipated degree of control of partial attacks.

The exact mechanism of SUDEP remains unknown, but it is very probable that cardiac arrhythmia during and between seizures plays a potential role ${ }^{8,18,24,25}$. Cardiorespiratory abnormalities are more often reported in patients with temporal lobe epilepsy, where there is evidence of ictal and interictal autonomic dysregulation, predominantly with sympathetic overactivity ${ }^{26}$. Alterations in heart rate variability have been reported not only in adults but also in children with epilepsy. Patients with epilepsy appear to have a reduction in some heart rate variability measures, suggesting a decreased sympathetic tone, which may be related to the drug therapy or to epilepsy itself ${ }^{27-29}$.

In our patients no history of heart disease was found among those deceased and no association was established with heart disease in any of the surgical candidates. As previously reported, even asymptomatic patients with epilepsy may have mild alterations in the electrocardiogram at rest such as faster ventricular rates ${ }^{30}$ or increases in the mean QTc interval during ictal period ${ }^{31}$.

People with epilepsy may die suddenly and unexpectedly without a structural pathological cause. Most SUDEP cases are likely to be related to seizures ${ }^{29}$. The fatal event generally occurred in association with generalized tonicclonic seizure ${ }^{8,18}$. Nashef et al. suggested that most cases of SUDEP represented ictal or postictal seizure deaths, occurring in individuals with a history of generalized tonic clonic seizures, and in both primary generalized and localization-related epilepsy ${ }^{32}$. No significant association between the type of epilepsy and the fatal outcome was observed in the patients assessed. Most of these patients were classified as having symptomatic epilepsy (84.1\% of surgically treated patients).

Hennessy et al., in a study of mortality after temporal lobe epilepsy surgery, verified that SUDEP rates were lower than those reported for similar patient populations with chronic epilepsy ${ }^{23}$. Sperling et al. suggested that elimination of seizures after surgery reduces mortality rates in individuals with epilepsy to a level indistinguishable from that of the general population, whereas patients with recurrent seizures continue to have high mortality rates ${ }^{33}$.

A major weakness of this study is that no definitive case of SUDEP could be confirmed, because no patient underwent necropsy examination. However, the age range of the patients who died and their otherwise healthy conditions makes it unlikely that causes other than potential intoxication with antiepileptic drugs or other substance might have been an external, non-SUDEP, cause of death. 
By all accounts, we obtained no evidence that this concurred to the fatal outcome of the patients who died.

Finally, we believe that a major finding here was that secondary generalized seizures in patients operated for refractory extratemporal epilepsies correlated with SUDEP. Thus, all efforts should be undertaken to eliminate this seizure type and the perspective of such control should be viewed as a clearly valid goal of extratemporal epilepsy surgery. Not infrequently, the results of presurgical evaluation in patients with extratemporal epilepsies point to epileptogenic zones which may not be thoroughly localizable or completely resectable. This is the case when, for instance, relevant irritative or ictal onset zones associated with dysplastic, gliotic or other lesion types involve eloquent cortex. Because the prevalent view is that resective surgery should be reserved only for those patients in whom complete seizure freedom is anticipated (or, at least, a major possibility), the possibility that subtotal resections (complemented or not by subpial transections, as an example) might completely control the generalized attacks while incompletely controlling partial attacks has not been explicitly explored. Our findings suggest that this may be a relevant issue which should be formally evaluated in future studies.

In conclusion, our data suggest a similar SUDEP incidence among operated and non operated patients. In the group of surgically treated patients, extratemporal refractory epilepsy and the presence of secondary generalized seizures significantly correlated to SUDEP and perhaps, in those patients, an interaction between the underlying disease and the generalized attacks may play a key role in the pathogenesis of SUDEP.

\section{REFERENCES}

1. Nashef L. Sudden unexpected death in epilepsy: terminology and definition. Epilepsia 1997;38 (Suppl 11):S6-S8.

2. Wannamaker BB. A perspective on death of persons with epilepsy. In: Lathers CM, Schraeder PL (Eds). Epilepsy and sudden death. New York and Basel, Marcel Deckker 1990:27-37.

3. Kloster R, Engelskjon T. Sudden unexpected death in epilepsy (SUDEP): a clinical perspective and a search for risk factors. J Neurol Neurosurg Psychiatry 1999;67:439-444.

4. Timmings PL. Sudden unexpected death in epilepsy: a local audit. Seizure 1993;2:287-290.

5. Mohanraj R, Norrie J, Stephen LJ, Kelly K, Hitiris N, Brodie MJ. Mortality in adults with newly diagnosed and chronic epilepsy: a retrospective comparative study. Lancet Neurol 2006;5:481-487.

6. Dasheiff RM. Sudden unexpected death in epilepsy: a series from an epilepsy surgery program and speculation on the relationship to sudden cardiac death. J Clin Neurophysiol 1991;8:216-222.

7. Johnston A, Smith P. Sudden unexpected death in epilepsy. Expert Rev Neurother 2007;7:1751-1761.
8. Tomson T, Walczak T, Sillanpaa M, Sander JW. Sudden unexpected death in epilepsy: a review of incidence and risk factors. Epilepsia 2005;46:54-61.

9. Langan Y. Sudden unexpected death in epilepsy (SUDEP): risk factors and case control studies. Seizure 2000;9:179-183.

10. Monté $\mathrm{CP}$, Arends JB, Tan IY, Aldenkamp AP, Limburg M, de Krom MC. Sudden unexpected death in epilepsy patients: risk factors. A systematic review. Seizure 2007;16:1-7.

11. Hirsch CS, Martin DL. Unexpected death in young epileptics. Neurology 1971;21:682-690.

12. Schwender LA, Troncoso JC. Evaluation of sudden death in epilepsy. Am J Forensic Med Pathol 1986;7:283-287.

13. Leestma JE, Kalelkar MB, Teas SS, et al. Sudden unexpected death associated with seizures: analysis of 66 cases. Epilepsia 1984;25:84-88.

14. Earnest MP, Thomas GE, Eden RA, et al. The sudden unexplained death syndrome in epilepsy: demographic, clinical and post-mortem features. Epilepsia 1992;33:310-316.

15. Kloster R, Engelskjon T. Sudden unexpected death in epilepsy (SUDEP): a clinical perspective and a search for risk factors. J Neurol Neurosurg Psychiatry 1999;67:439-444.

16. Walczak TS, Leppik IE, D'Amelio M, et al. Incidence and risk factors for sudden unexpected death in epilepsy: a prospective cohort study. Neurology 2001;56:519-525.

17. Tomson T, Nashef L, Ryvlin P. Sudden unexpected death in epilepsy: current knowledge and future directions. Lancet Neurol 2008;7:1021-1031.

18. Nilsson L, Farahmand BY, Persson PG, et al. Risk factors for sudden unexpected death in epilepsy: a case-control study. Lancet 1999;353:888-893.

19. Engel J Jr. Report of the ILAE classification core group. Epilepsia 2006;47: 1558-1568.

20. Leestma JE, Walczak T, Hughes JR, et al. A prospective study on unexpected death in epilepsy. Ann Neurol 1989;26:195-203.

21. Engel J Jr, Van Ness PC, Rasmussen TB, Ojemann LM. Outcome with respect to epileptic seizures. In: Engel J Jr (Ed). Surgical treatment of the epilepsies. New York, Raven Press 1993:609-621.

22. Elsharkawy AE, Pannek $H$, Schulz $R$, et al. Outcome of extratemporal epilepsy surgery experience of a single center. Neurosurgery 2008;63:516526.

23. Hennessy MJ, Langan $Y$, Elwes RD, Binnie CD, Polkey CE, Nashef L. A study of mortality after temporal lobe epilepsy surgery. Neurology 1999:53:1276-1283

24. Nashef L, Walker F, Allen P, Sander JWAS, Shorvon SD , Fisch DR. Apnea and bradychardia during epileptic seizures: relation to sudden death in epilepsy. J Neurol Neurosurg Psychiatry 1996;60:297-300.

25. Stöllberger C, Finsterer J. Cardiorespiratory findings in sudden unexplained /unexpected death in epilepsy (SUDEP). Epilepsy Res 2004;59:51-60.

26. Schuele SU, Bermeo AC, Alexopoulos AV, et al. Video-electrographic and clinical features in patients with ictal asystole. Neurology 2007;69: 423-424.

27. Tomson T, Ericson M, Ihrman C, Lindblad LE. Heart rate variability in patients with epilepsy. Epilepsy Res 1998;30:77-83.

28. Ferri R, Curzi-Dascalova L, Arzimanoglou A, et al. Spectral analysis of heart rate variability during sleep in children with partial epilepsy. J Sleep Res 2002:11:153-160.

29. Naschef L, Hindocha N, Markoff A. Risk factors in sudden death in epilepsy (SUDEP): the quest for mechanisms. Epilepsia 2007;48:859-871.

30. Drake $M E$, Reider $C R$, Kay A. Electrocardiography in epilepsy patients without cardiac symptoms. Seizure 1993;2:63-65.

31. Tavenor SJ, Brown SW, Tavernor RM, Gifford C. Electrocardiograph QT lengthening associated with epileptiform EEG discharges: a role in sudden unexplained death in epilepsy? Seizure 1996:5:79-83.

32. Nashef L, Garner S, Sander JWAS, Fisch DR, Shorvon SD. Circumstances of death in sudden death in epilepsy: interviews of bereaved relatives. J Neurol Neurosurg Psychiatry 1998;64:349-352.

33. Sperling MR, Feldman H, Kinman J, Liporace JD, O'Connor MJ. Seizure control and mortality in epilepsy. Ann Neurol 1999;46:45-50. 